\title{
Laparoscopy in uterine cervical cancer. Current state and literature review
}

\author{
Laparoscopia no câncer de colo uterino. Estado atual e revisão da literatura
}

Audrey Tieko Tsunoda, ACBC-SP¹; Carlos Eduardo Mattos da Cunha Andrade ${ }^{1}$; Marcelo Andrade Vieira ${ }^{1}$; Ricardo dos Reis ${ }^{1}$

\begin{abstract}
A B S T R A C T
Cervical cancer remains the most frequent gynecological tumor in Brazil and other developing countries. Minimally invasive techniques, especially laparoscopy, have been increasingly employed in such tumors. This article aims to describe the main applications of laparoscopy in the treatment and staging of cervical cancer. In the early stages, it is possible to provide a fertilitypreserving surgery in the form of radical trachelectomy and, in a study protocol, the function-preserving surgery, avoiding parametrectomy and the associated morbidity. A fully laparoscopic radical hysterectomy is fairly standard in the literature and has the tendency to become the standard of care in early cases, for patients who want to bear no more children. In advanced stages, minimally invasive surgery can offer ovarian transposition, with intent to prevent actinic castration, without upsetting the time for the start of radiotherapy and chemotherapy. Staging laparoscopic surgery, including pelvic and para-aortic lymphadenectomy, has been the subject of studies, since it has the potential to modify the extension of radiotherapy depending on the extent of lymph node spread.
\end{abstract}

Key words: Colonic Neoplasms. Laparoscopy. Neoplasm Staging. Therapeutics. Hysterectomy. Lymph Node Excision.

\section{INTRODUCTION}

$\mid \mathrm{n}$ developing countries, cervical cancer is the most common cause of cancer death in women, accounting for the highest number of years of life lost due to cancer. It is most commonly diagnosed around the fifth decade of life, ie, several years earlier than the average age for breast, lung and ovarian cancers. The cervical cancer in the early stages is highly curable when treated properly'. Laparoscopy has now been applied for the management of cervical cancer both at early and advanced stages ${ }^{2}$.

\section{Early-stage cervical cancer}

In 1912, Wertheim (Austria, 1864-1920), who designed the surgical treatment for cervical cancer used today (radical hysterectomy), published his first results. In 1944, Meigs (United States, 1892-1963) added the bilateral pelvic lymphadenectomy. The procedure became known as the Wertheim-Meigs surgery ${ }^{3}$.

The Wertheim-Meigs surgery includes the exeresis of the uterus, $25 \%$ of the proximal vagina, the uterosacral ligaments, the uterovesical ligaments and both parametria ${ }^{4}$. Moreover, a bilateral pelvic lymphadenectomy is held, which includes the four major lymph node groups: ureteral, obturator, hypogastric and pelvic. This is the classical treatment of early stages of cervical cancer ${ }^{1}$.
Laparoscopy has been applied in the realization of some steps or even the complete procedure. The literature thus describes a combination of routes and procedures for early cervical cancer, such as pelvic lymphadenectomy, laparoscopic radical hysterectomy, laparoscopic-assisted radical vaginal hysterectomy, laparoscopic-assisted radical vaginal trachelectomy and vaginal-assisted radical laparoscopic trachelectomy².

\section{Laparoscopic Radical Hysterectomy}

The first laparoscopic radical hysterectomy with pelvic and para-aortic lymphadenectomy was performed by Nezhat et al. In 1989 and described in the literature in the early $90 \mathrm{~s}^{5}$. Since then, several authors have published their experience with the procedure. In the series described by the MD Anderson Cancer Center all patients with cervical cancer undergoing laparoscopic radical hysterectomy showed clear margins and no patient required conversion to laparotomy. This study was the first to demonstrate a median hospital stay of one day after this type of procedure ${ }^{6}$.

Several studies confirm that laparoscopy is associated with better postoperative outcome compared with laparotomy, ie, less intraoperative bleeding, smaller incisions, shorter hospital stays, without compromising the size of the radical hysterectomy specimen. As for cancer

1. Departamento de Ginecologia Oncológica, Hospital de Câncer de Barretos / Fundação Pio XII, Barretos, SP, Brasil. 
prognosis, it seems to have similar results to those of laparotomy surgery ${ }^{6-9}$. Moreover, laparoscopic radical hysterectomy can be performed in developing countries with quality similar to the technique used in major world reference centers ${ }^{10}$. A recent study evaluated the role of laparoscopic radical hysterectomy compared with laparotomy radical hysterectomy in patients with tumors $\geq 3 \mathrm{~cm}$. The authors concluded that the laparoscopic approach may be used for this surgical approach without harm for the treatment of patients with this tumor size ${ }^{11}$.

In order to assess whether minimally invasive surgery presents results similar to laparotomy, the prospective, randomized LACC (Laparoscopic Approach to Cervical Cancer, MD Anderson Cancer Center, NCT00614211, www. clinicaltrials.gov) clinical trials being conducted. This unpublished, multicenter study has the participation of a Brazilian center (Hospital de Câncer de Barretos, HCB). Through it, one can measure the cancer effectiveness, lower morbidity and the potential gain in quality of life offered by laparoscopy and robotics ${ }^{12}$.

In $\mathrm{HCB}$, this procedure was first performed laparoscopically in 2009, with an increasing number of cases over the past three years (Table 1).

\section{Laparoscopic lymphadenectomy}

In cervical cancer lymph node involvement is an important prognostic factor ${ }^{1}$. Approximately $7 \%$ to $15 \%$ of patients with cervical cancer in the early stages presents with compromised pelvic lymph nodes. The number of lymph nodes removed is an important prognostic factor ${ }^{13}$ and can be equal or even superior in laparoscopy ${ }^{9}$.

The realization of the pelvic and para-aortic lymphadenectomy by laparoscopy is safe, feasible and displays acceptable complications rates within Oncologic Gynecology 14,15 .

\section{Lymphatic mapping}

Lymphatic mapping in cervical cancer can be accomplished by injection of dye (patent blue, indocyanine green) and radiopharmaceutical in the cervix. It is a feasible procedure, but with limitations in terms of sensitivity and specificity ${ }^{1,16}$. The technique for surgical detection of the sentinel lymph node can be performed entirely by laparotomy or laparoscopy².

In HCB the laparoscopic approach is offered to all patients with indication of radical hysterectomy, ie, cervical cancer confined to the cervix, in stages $|A|$ with lymphovascular invasion, IA2 and IB1. Only those patients randomized to the laparotomy for the LACC research protocol (previously cited, NCT00614211, www.clinicaltrials.gov) have the surgery performed in the conventional manner. Whenever possible, we research the sentinel lymph node with combined technique, patent blue and radiopharmaceutical. The sentinel lymph node is sent to perioperative pathological examination, followed by systematic pelvic lymphadenectomy. If the sentinel node is negative, the radical hysterectomy indication remains. If it is positive, hysterectomy is abandoned and lymphadenectomy is extended to the para-aortic. In cases without sentinel node search, we carry out a systematic iliac and obturator bilateral lymphadenectomy, with selection of the largest and/or suspected lymph nodes for perioperative pathological examination. If lymph node involvement is detected, radical hysterectomy is abandoned and the lymphadenectomy is extended to the retroperitoneum (para-aortic), till the level of the left renal vein.

\section{trachelectomy}

Fertility-sparing treatment - radical

With the increased incidence of cervical cancer in younger age groups, with sometimes undefined progeny, fertility-preserving techniques have become a demand for the surgeon and a hope for patients.

Infertility generated by cancer can cause depression, stress and sexual dysfunction in young women and the preserving alternative should be considered and discussed with the patient.

Conducted by Daniel Dargent since 1987, radical trachelectomy was first described as totally vaginal. It includes the removal of the cervix, the vaginal cuff and parametria, keeping the uterine body, fundus and

Table 1 - Totally Laparoscopic Radical Hysterectomy.

\begin{tabular}{lc}
\hline & N \\
\hline Number of procedures & 62 \\
Surgical time & $259.1 \mathrm{~min}$ \\
First 32 & $222.4 \mathrm{~min}$ \\
Last 30 & \\
$p=0.024$ & \\
Perioperative bleeding & $134.7 \mathrm{ml}$ \\
First 32 & $99.7 \mathrm{ml}$ \\
Last 30 & $5 \quad(10 \%)$ \\
$p=0.316$ & 1 \\
Perioperative complications & 1 \\
Bladder injury & 1 \\
Ureteral injury & 2 \\
Neural injury & 0 \\
Vascular injury & 2 \\
Reoperations/reinterventions & $7(5 \%)$ \\
Conversions & 1 \\
Late complications & 1 \\
Ureteral stricture & 2 \\
Urinary retention & 2 \\
Dehiscence of vaginal cuff & 1 \\
Peripheral neuropathy & Urinary fistula
\end{tabular}

Source: Department of Gynecology Oncology, Hospital de Câncer de Barretos / Fundação Pius XII (2009-2013). 
attachments. Concomitant pelvic lymphadenectomy, in turn, was conducted via laparoscopic ${ }^{17}$.

The vaginal radical trachelectomy is the most performed fertility-sparing procedure in the world for early cervical cancer. More than 700 cases have been reported, with later 250 pregnancies that generated about 100 live births. Some groups have shown success in up to $80 \%$ of pregnancy attempts with the use of assisted reproduction therapy ${ }^{18}$.

The indications for the procedure are: age $\leq 45$ years, desire to preserve fertility, fertile patient, stages IA1 with invasion of lynphovascular spaces, IA2 and IB1 $<2 \mathrm{~cm}$, with magnetic resonance imaging showing no parametrial invasion and no evidence of lymph node or distant metastases $^{19}$. Factors such as invasion of lymphovascular space, high grade tumors and the diameter $>2 \mathrm{~cm}$ can be considered contraindications for fertility-preserving surgery ${ }^{18}$ A recent study showed that radical trachelectomy could be indicated in patients with tumor size between 2 and $4 \mathrm{~cm}$ in $30 \%$ of patients who would be candidates for fertilityloosing radical surgery ${ }^{20}$, but the current consensus is to indicate this procedure in patients with tumors up to $2 \mathrm{~cm}$.

Laparotomy started to be used in radical trachelectomy over the past decade ${ }^{18}$. In 500 patients undergoing abdominal radical trachelectomy, there was $10 \%$ conversion to radical hysterectomy, $0.4 \%$ deaths and three intraoperative complications. During 32 months of follow-up, recurrence was $3.8 \%$. Of those who tried to conceive, $60 \%$ were able to get pregnant, with $40 \%$ term pregnancies ${ }^{21}$.

The techniques of radical trachelectomy by laparoscopy and by robotic surgery have been feasible in initial experiments, with low rates of intraoperative complications and no conversion to laparotomy with seasoned teams ${ }^{22}$.

The laparoscopic approach has been less used, possibly because of the technical difficulty to perform the suturing of the isthmus / residual cervix to the vaginal cuff. However, for teams with experience in laparoscopic radical surgery for cervical cancer, it remains an alternative access with reduced morbidity, similar oncological outcomes and good fertility rates ${ }^{23}$.

In countries where the access to robotic surgery is limited, laparoscopic surgery may represent a good option among the minimally invasive techniques ${ }^{23}$. At we HCB perform vaginal-assisted laparoscopic radical trachelectomy, using the vaginal route only to amputation of the cervix and reanastomosis of the remaining uterus to the vagina.

\section{Cervical Cancer}

\section{Less Radical Treatment for Early Stage}

As already described, treatment options for patients in early stages of cervical cancer are surgery (radical hysterectomy or radical trachelectomy) or radiotherapy (with or without chemotherapy) 1 . The choice between these treatment modalities involves multiple factors, such as the most common morbidities of each treatment, patient's performance status, desire to maintain fertility and prognostic factors. Radical surgery is the standard treatment for young patients with good performance status.

The most frequent and significant sequelae presented in radical surgical treatment are due to the removal of the parametrium, which contains autonomic nerve fibers associated with bladder, bowel and sexual function ${ }^{24}$. Removal of the parametrium in patients in early stages that do not have poor prognostic factors (larger lesions with lymphovascular invasion or deep stromal invasion) was questioned from studies that identified a small percentage of parametrial involvement in this subgroup ${ }^{25}$. Due to the morbidity of parametrectomy, some services are developing an autonomic nerve-sparing radical hysterectomy, both minimally invasive and by laparotomy, in order to decrease the nervous sequelae in the vagina, bladder and rectum. A recent study has shown that this technique is associated to lower anorectal dysfunction ${ }^{26}$. Another long-term study showed that laparoscopy for radical hysterectomy improves nervous dissection and preservation due to the better magnification ${ }^{27}$.

The first study to evaluate the possibility of treating low-risk women in the early stages without resection of the parametrium was conducted by Kinney et al. In 1995. They analyzed 387 women with cervical cancer who underwent radical hysterectomy. Of these, $83(21.4 \%)$ were classified as belonging to a subgroup of low risk among patients in early stages of cervical cancer. The criteria adopted were only cases with histological subtype of squamous cell carcinoma, larger tumor diameter less than $2 \mathrm{~cm}$ and no lymphovascular invasion. In this low-risk subgroup, no case had parametrial involvement, and the authors raised the possibility of a less radical treatment ${ }^{28}$.

In 2002, Covens et al. evaluated the incidence and predictors of parametrial involvement in women undergoing radical hysterectomy for cervical cancer in stages la1 through IB1. Of 842 patients, 33 (4\%) had parametrial involvement, and as compared to patients without involvement, patients were older, had larger tumor diameter, increased incidence of lymphovascular invasion, higher frequency of histological grades 2 or 3 , deeper stromal invasion and higher incidence of metastases to pelvic lymph nodes. The incidence of parametrial commitment in patients with tumor $\leq 2 \mathrm{~cm}$, negative pelvic lymph nodes and depth of invasion $\leq 10 \mathrm{~mm}$ was $0.6 \%{ }^{29}$.

The MD Anderson Cancer Center conducted an analysis of all women undergoing radical hysterectomy with pelvic lymphadenectomy for cervical cancer between 1990 and 2006. They included 350 women, of whom 27 (7.7\%) had parametrial commitment with statistically significant increased frequency and: tumor size $>2 \mathrm{~cm}(p=0.001)$, histological grade $3(p=0.01)$, lymphovascular invasion $(p=0.002)$ and pelvic lymph node metastases $(p<0.001)$. Patients with squamous histology, adenocarcinoma or adenosquamous carcinoma, with tumor smaller than $2 \mathrm{~cm}$ 
and without lymphovascular invasion showed no parametrial commitment ${ }^{25}$.

The prospective study by Pluta et al. showed that in patients with negative sentinel lymph node frozen section radicality reductio is safe without performing the parametrectomy in the subgroup of patients with tumors $<2 \mathrm{~cm}$ and with stromal invasion $<50 \%$. Of 60 patients, 55 had a negative sentinel node, and after simple vaginal hysterectomy and laparoscopic lymphadenectomy no recurrence occurred in a 47-month median follow-up ${ }^{30}$.

The standardization of prognostic criteria for the performance of function-conserving surgery is not yet established. A South Korean multicenter study compared the most commonly used criteria for itss indication: 1) Tumor $\leq 1 \mathrm{~cm}, 2$ ) tumor $\leq 1 \mathrm{~cm}$ and stromal invasion $\leq 5 \mathrm{~mm}, 3$ ) Tumor $\leq 1 \mathrm{~cm}$ and absence of lymphovascular invasion, and 4) tumor $\leq 1 \mathrm{~cm}$, stromal invasion $\leq 5 \mathrm{~mm}$ and absence of lymphovascular invasion. Among these, the criterion Tumor $\leq 1 \mathrm{~cm}$ seems to be safe enough for the indication of treatment without parametrectomy ${ }^{31}$.

To evaluate the obstetric results of parametrium preservation, Raju et al. analyzed a subgroup of low-risk patients, comparing radical vaginal trachelectomy with simple trachelectomy, and there was no significant difference in prognosis between the methods. However, the morbidity related to treatment was reduced and the potential for fertility increased in the group submitted to simple trachelectomy ${ }^{32}$.

To evaluate safety and application of functionconserving surgery in women with early stage cervical cancer and favorable pathologic criteria, the MD Anderson Cancer Center team is conducting a multicenter, prospective study, with the participation of the Hospital de Câncer de Barretos (NCT01048853, www.clinicaltrials.gov). The inclusion criteria are: cases of cervical cancer in IA2 / IB1 stages with tumor $\leq 2 \mathrm{~cm}$ without lymphovascular invasion, with histology of squamous cell carcinoma (any grade) or adenocarcinoma (grades 1 or 2), cone margin and endocervical canal curettage negative for invasive, high-grade squamous intraepithelial lesions, and stromal invasion $<10 \mathrm{~mm}$. The sample size was calculated in 100 patients and the protocol adopts strict security criteria for patients, the study being suspended if there are two or more relapses.

Another ongoing study in this context is the SHAPE Trial (NCT 01658930, www.clinicaltrials.gov), a Canadian randomized trial that includes patients at stages IA2 / IB1, with favorable histology (squamous cell carcinoma, adenocarcinoma or adenosquamous carcinoma), tumor $<2 \mathrm{~cm}$, stromal invasion $<50 \%$ and MRI or CT scan without evidence of lymph node involvement. Women included are randomized, the control group undergoing radical hysterectomy with pelvic lymphadenectomy (with or without sentinel lymph node) and the experimental groups undergoes simple hysterectomy with superior colpectomy and pelvic lymphadenectomy (with or without sentinel lymph node). They will assess postoperative quality of life, disease-free interval and overall survival ${ }^{33}$.

Function-conserving surgery may represent a therapeutic option in the early stages with favorable prognostic criteria. But ongoing studies should define what criteria should be adopted so that low-risk patients benefit from this morbidity reduction without compromising their good prognosis.

\section{ADVANCED STAGES}

\section{Concept and current treatment of locally advanced cervical cancer}

The tumor of the cervix that goes beyond the cervical ring is considered locally advanced cervical cancer according to the International Federation of Gynecology and Obstetrics - $\mathrm{FIGO}^{34}$. Some centers, like the Cancer Hospital of Barretos (HCB), adopt the concept of locally advanced disease, even for tumors confined to the cervix and upper third of the vagina, but measuring more than $4 \mathrm{~cm}$ in the major axis (IB2 and IIA2 stages) ${ }^{1}$. This is because, for the vast majority of these cases, there is need for treatment with pelvic radiotherapy to offer greater overall survival and disease-free interval ${ }^{35,36}$. The traditional criteria of adjuvant radiotherapy indication for cervical cancer were established from the higher chance of relapse when there is parametrial invasion, compromised pelvic lymph nodes and positive resection margins ${ }^{36}$. Other minor factors, when combined, also confer higher recurrence risk, such as angiolymphatic invasion, tumor size $>4 \mathrm{~cm}$ or deep cervical stromal invasion ${ }^{37}$. It is known that radical surgery for primary tumor, followed by adjuvant therapy with radiation, presents more complications than exclusive radiotherapy and chemotherapy, with no benefits in terms of local control and overall survival ${ }^{38}$.

Therefore, the current treatment for locally advanced cervical cancer, stages IB2 to IVA, is pelvic radiotherapy combined with radiosensitising chemotherapy, followed by cervical high-dose brachytherapy ${ }^{1}$.

\section{Locally advanced cervical cancer and evaluation of lymph node status}

To date, FIGO did has not included the evaluation of lymph nodes as part of cervical cancer staging, which remains eminently clinical ${ }^{34}$. However, lymph node involvement remains a significant prognostic factor that can change the therapeutic approach and hence modify these patients' the survival rates $^{36}$. In the treatment guidelines suggested by the American National Comprehensive Cancer Network - NCCN, the assessment of lymph node stage prior to the combined treatment can be done through imaging or minimally invasive surgery $^{39}$. In the presence of involved para-aortic lymph nodes, there is indication of radiotherapy with field extension to this topography ${ }^{39}$. 
Between $12 \%$ and $25 \%$ of locally advanced cervical cancers have para-aortic lymph node metastases. Computed tomography, magnetic resonance imaging and PET-CT have been used to assess pretreatment lymph node status in such patients. The chances of false-negative results in this group ranges from $10 \%$ to $28 \%$ in several series ${ }^{40}$. For women with positive pelvic lymph nodes, the chance of positive para-aortic lymph nodes, even with negative PET-CT, is $20 \%$ to $25 \%{ }^{40,41}$. Thus, surgery is considered more appropriate than the imaging studies available today for assessing lymph node status in locally advanced cervical cancer.

\section{Pretreatment surgical staging}

The surgical staging prior to combined radiotherapy and chemotherapy for the treatment of advanced cervical cancer has the potential benefit to modify the extent of the therapeutic field set to radiotherapy (extension for para-aortic space). Moreover, removal of lymph nodes enlarged due to involvement by tumor disease provides a reduction in volume, with the increase in efficacy of radiotherapy in the para-aortic space. This explains why, in order to eliminate macroscopic disease $>2 \mathrm{~cm}$ in diameter, it would require a radiation dose of at least $6000 \mathrm{cGy}$, prohibitive in this topography, even with the use of intensity modulated radiotherapy technology (IMRT). In the absence of macroscopic disease, with the intention of adjuvant therapy after removal of the lymph nodes, the recommended effective dose for radiobiological effect is about 4500 cGy, offered with greater safety in a conventional planning in three dimensions ${ }^{42}$.

Therefore, removal of committed para-aortic lymph nodes previous to combined treatment can modify the field and reduce the need of high radiation doses on the site.

Three studies conducted by the Gynecologic Oncology Group - GOG - identified by the numbers 85, 120 and 165, analyzed the potential benefit of surgical staging prior to the combined treatment with radiotherapy and chemotherapy. Among the surgically staged 555 patients, overall survival and four-year disease-free interval were, respectively, $54 \%$ and $49 \%$. On the other hand, among the 130 patients who underwent clinical and radiological staging, these percentages were $40 \%$ and $36 \%$, respectively ${ }^{43}$. Although these studies did not intend to evaluate this issue, that difference was statistically significant.

When comparing the survival of women with para-aortic lymph node metastasis $\leq 5 \mathrm{~mm}$ in diameter undergoing surgery, it was observed that it was similar to women with negative para-aortic lymph nodes $(70 \%$ in four years $)^{40,41}$. Among the patients with lymph node metastasis $>5 \mathrm{~mm}$ and / or capsular involvement and / or fixed nodes, the overall survival rate at four years was greater than $30 \%$, much lower than in previous groups but greater than the overall survival of patients in FIGO stage IVB (distant metastases ${ }^{34,40,41}$.

Other groups performing surgical staging prior to combined treatment corroborate these results, observing low morbidity, especially after reaching the procedure's learning curve ${ }^{44}$.

The first large prospective, randomized clinical trial in this scenario is being conducted by the University Charité in Berlin, sponsored by the AGO (Arbeitsgemeinschaft Gynäkologische Onkologie - German Study Group in Gynecologic Oncology). In this study, 250 women with cervical cancer FIGO stage IIB to IVA were randomized to staging minimally invasive surgery followed by radiotherapy and chemotherapy versus radiotherapy and conventional chemotherapy. A total of 16 German institutions and one Brazilian (HCB) participated in the study recruitment, ended in 2013 . The preliminary results are awaited for the next months ${ }^{45}$.

More specifically, for patients with positive PET$\mathrm{CT}$ for the pelvis and negative for the para-aortic space, the EPLND study provides randomization for surgery followed by radiotherapy and chemotherapy versus conventional radiotherapy and chemotherapy ${ }^{45}$.

Currently, the recommendation remains to offer minimally invasive surgical staging for patients with locally advanced cervical cancer with the aim of adjusting the radiation field to the real extent of the disease ${ }^{38}$. The group of patients that seem to benefit more from the surgical evaluation approach is the one with suspected pelvic lymph nodes at imaging tests, preferably PET-CT ${ }^{40}$.

\section{FINAL CONSIDERATIONS}

Early cervical cancer can be adequately addressed through minimally invasive surgery, with likely similar oncological efficacy, and apparent reduction of morbidity. For the preservation of fertility, laparoscopy offers adequate lymph node staging and treatment with oncological results similar to radical surgery in selected patients. In this context, the function-preserving surgery has been the subject of studies and has the potential to become the treatment of choice for patients with early tumors of very good prognosis. In advanced cervical cancer, minimally invasive surgical staging can tailor the radiation therapy field and reduce the amount of disease to be treated, with potential gain in the disease-free interval and overall survival. Studies, including in partnership with Brazilian institutions, are underway to clatiry the evidence supporting the potential benefits of minimally invasive approaches to cervical cancer. 
O câncer de colo uterino permanece o tumor ginecológico mais incidente no Brasil e em diversos países em desenvolvimento. As técnicas minimamente invasivas, principalmente a videolaparoscopia, têm sido progressivamente mais empregadas nestes tumores. Este artigo tem o objetivo de descrever as principais aplicações da videolaparoscopia no tratamento e no estadiamento do câncer de colo. Para os estádios iniciais, é possível oferecer a cirurgia preservadora de fertilidade, na forma de traquelectomia radical e, em protocolo de estudo, na cirurgia conservadora de função, evitando-se a parametrectomia e a morbidade associada. A histerectomia radical totalmente videolaparoscópica está adequadamente padronizada na literatura e tem a tendência de se tornar o padrão de tratamento nos casos iniciais, para pacientes com prole definida. Nos estádios avançados, a cirurgia minimamente invasiva pode oferecer a transposição ovariana, com intenção de evitar a castração actínica, sem prejudicar o tempo para o início do tratamento radioterápico e quimioterápico. A cirurgia laparoscópica estadiadora, incluindo linfadenectomia pélvica e paraórtica, tem sido alvo de estudos, uma vez que tem o potencial de modificar a extensão do tratamento radioterápico, na dependência da extensão da disseminação linfonodal.

\section{Descritores: Neoplasias do Colo. Laparoscopia. Estadiamento de Neoplasias. Terapêutica. Histerectomia. Excisão de Linfonodo.}

\section{REFERENCES}

1. Waggoner SE. Cervical cancer. Lancet. 2003;361(9376):2217-25.

2. Cho JE, Liu C, Gossner G, Nezhat FR. Laparoscopy and gynecologic oncology. Clin Obstet Gynecol. 2009;52(3):313-26.

3. Meigs JV. Radical hysterectomy with bilateral pelvic lymph node dissections; a report of 100 patients operated on five or more years ago. Am J Obstet Gynecol. 1951;62(4):854-70.

4. Piver MS, Rutledge F, Smith JP. Five classes of extended hysterectomy for women with cervical cancer. Obstet Gynecol. 1974;44(2):265-72.

5. Nezhat CR, Burrell MO, Nezhat FR, Benigno BB, Welander CE. Laparoscopic radical hysterectomy with paraaortic and pelvic node dissection. Am J Obstet Gynecol. 1992;166(3):864-5.

6. Ramirez PT, Slomovitz BM, Soliman PT, Coleman RL, Levenback C. Total laparoscopic radical hysterectomy and lymphadenectomy: the M. D. Anderson Cancer Center experience. Gynecol Oncol. 2006;102(2):252-5

7. Abu-Rustum NR Gemignani ML, Moore K, Sonoda Y, Venkatraman E, Brown C, et al. Total laparoscopic radical hysterectomy with pelvic lymphadenectomy using the argon-beam coagulator: pilot data and comparison to laparotomy. Gynecol Oncol. 2003;91(2):402-9. Erratum in: Gynecol Oncol. 2004;93(1):275

8. Gil-Moreno A, Díaz-Feijoo B, Roca I, Puig O, Pérez-Benavente MA, Aguilar I, et al. Total laparoscopic radical hysterectomy with intraoperative sentinel node identification in patients with early invasive cervical cancer. Gynecol Oncol. 2005;96(1):187-93.

9. Frumovitz M, dos Reis R, Sun CC, Milam MR, Bevers MW, Brown J, et al. Comparison of total laparoscopic and abdominal radical hysterectomy for patients with early-stage cervical cancer. Obstet Gynecol. 2007;110(1):96-102.

10. Pareja R, Nick AM, Schmeler KM, Frumovitz M, Soliman PT, Buitrago CA, et al. Quality of laparoscopic radical hysterectomy in developing countries: a comparison of surgical and oncologic outcomes between a comprehensive cancer center in the United States and a cancer center in Colombia. Gynecol Oncol. 2012:125(2):326-9

11. Kong TW, Chang SJ, Lee J, Paek J, Ryu HS. Comparision of laparoscopic versus abdominal readical hysterectomy for FIGO stage IB and IIA cervical cancer with tumor diameter of $3 \mathrm{~cm}$ or greater. Int J Gynecol Cancer. 2014;24(2):280-8.

12. Obermair A, Gebski V, Frumovitz M, Soliman PT, Schmeler KM, Levenback $C$, et al. A phase III randomized clinical trial comparing laparoscopic or robotic radical hysterectomy with abdominal radical hysterectomy in patients with early stage cervical cancer. $J$ Minim Invasive Gynecol. 2008;15(5):584-8.

13. Fregnani JH, de Oliveira Latorre Mdo R, Novik PR, Lopes $A$, de Oliveira JC, Tsunoda AT, et al. Extent of pelvic lymphadenectomy in women with squamous cell carcinoma of the uterine cervix: is there any prognostic value? J Surg Oncol. 2009;100(3):252-7.

14. Magrina JF, Kho RM, Weaver AL, Montero RP, Magtibay PM. Robotic radical hysterectomy: comparison with laparoscopy and laparotomy. Gynecol Oncol. 2008;109(1):86-91.

15. Tillmanns T, Lowe MP. Safety, feasibility, and costs of outpatient laparoscopic extraperitoneal aortic nodal dissection for locally advanced cervical carcinoma. Gynecol Oncol. 2007;106(2):3704

16. Reis R, Tavares EB, Amaral B, Monego HI, Binda M, Magno V, et al. Sentinel lymph node identification in patients with stage IB1 invasive cervical carcinoma. Curr Cancer Ther Rev. 2007;3(3):209-14

17. Dargent D, Martin X, Sacchetoni A, Mathevet P. Laparoscopic vaginal trachelectomy: a treatment to preserve the fertility of cervical carcinoma patients. Cancer. 2000;88(8):1877-82.

18. Plante M, Gregoire J, Renaud MC, Roy M. The vaginal radical trachelectomy: an update of a series of 125 cases and 106 pregnancies. Gynecol Oncol. 2011;121(2):290-7.

19. Diaz JP, Sonoda Y, Leitao MM, Zivanovic O, Brown CL, Chi DS, et al. Oncologic outcome of fertility-sparing radical trachelectomy versus radical hysterectomy for stage IB1 cervical carcinoma. Gynecol Oncol. 2008;111(2):255-60.

20. Wethington SL, Sonoda Y, Park KJ, Alektiar KM, Tew WP, Chi DS, et al. Expanding the indications for radical trachelectomy: a report on 29 patients with stage IB1 tumors measuring 2 to 4 centimeters. Int J Gynecol Cancer. 2013;23(6):1092-8.

21. Pareja R, Rendón GJ, Sanz-Lomana CM, Monzón O, Ramirez PT. Surgical, oncological, and obstetrical outcomes after abdominal radical trachelectomy - A systematic literature review. Gynecol Oncol. 2013;131(1):77-82.

22. Ramirez PT, Schmeler KM, Malpica A, Soliman PT. Safety and feasibility of robotic radical trachelectomy in patients with earlystage cervical cancer. Gynecol Oncol. 2009;116(3):512-5.

23. Lu Q, Zhang Y, Liu C, Wang S, Guo S, Zhang Z. Total laparoscopic radical trachelectomy in the treatment of early squamous cell cervical cancer: a retrospective study with 8-year follow-up. Gynecol Oncol. 2013;130(2):275-9.

24. Schmeler KM, Frumovitz M, Ramirez PT. Conservative management of early stage cervical cancer: is there a role for less radical surgery? Gynecol Oncol. 2011;120(3):321-5.

25. Frumovitz M, Sun CC, Schmeler KM, Deavers MT, Dos Reis R, Levenback CF, et al. Parametrial involvement in radical hysterectomy specimens for women with early-stage cervical cancer. Obstet Gynecol. 2009;114(1):93-9.

26. Loizzi V, Cormio G, Lobascio PL, Marino F, De Fazio M, Falagario $M$, et al. Bowel dysfunction following nerve-sparing radical hysterectomy for cervical cancer: a prospective study. Oncology. 2014:86(4):239-43. 
27. Puntambekar SP, Lawande A, Puntambekar S, Joshi S, Kumar S, Kenawadekar R. Nerve-sparing radical hysterectomy made easy by laparoscopy. J Minim Invasive Gynecol. 2014;21(5):732.

28. Kinney WK, Hodge DO, Egorshin EV, Ballard DJ, Podratz KC. Surgical treatment of patients with stages IB and IIA carcinoma of the cervix and palpably positive pelvic lymph nodes. Gynecol Oncol. 1995; 57(2):145-9.

29. Covens A, Rosen B, Murphy J, Laframboise S, DePetrillo AD, Lickrish $G$, et al. How important is removal of the parametrium at surgery for carcinoma of the cervix? Gynecol Oncol. 2002;84(1):145-9.

30. Pluta M, Rob L, Charvat M, Chmel R, Halaska M Jr, Skapa P, et al. Less radical surgery than radical hysterectomy in early stage cervical cancer: a pilot study. Gynecol Oncol. 2009;113(2):181-4.

31. Kim HS, Choi CH, Lim MC, Chang SJ, Kim YB, Kim MA, et al. Safe criteria for less radical trachelectomy in patients with early-stage cervical cancer: a multicenter clinicopathologic study. Ann Surgical Oncol. 2011;19(6):1973-9.

32. Raju SK, Papadopoulos AJ, Montalto SA, Coutts M, Culora G, Kodampur $M$, et al. Fertility-sparing surgery for early cervical cancer-approach to less radical surgery. Int J Gynecol Cancer. 2012;22(2):311-7.

33. NCIC Clinical Trials Group. Radical versus simple hysterectomy and pelvic node dissection in patients with early stage cervical câncer. NCT 01658930. clinical trials.gov: clinical trials.gov. The SHAPE Trial (2013)

34. Pecorelli S, Zigliani L, Odicino F. Revised FIGO staging for carcinoma of the cervix. Int J Gynaecol Obstet. 2009;105(2):107-8.

35. Morris M, Eifel PJ, Lu J, Grigsby PW, Levenback C, Stevens RE, et al. Pelvic radiation with concurrent chemotherapy compared with pelvic and para-aortic radiation for high-risk cervical cancer. $\mathrm{N}$ Engl J Med. 1999:340(15):1137-43.

36. Peters WA 3rd, Liu PY, Barrett RJ 2nd, Stock RJ, Monk BJ, Berek JS, et al. Concurrent chemotherapy and pelvic radiation therapy compared with pelvic radiation therapy alone as adjuvant therapy after radical surgery in high-risk early-stage cancer of the cervix. J Clin Oncol. 2000;18(8):1606-13.

37. Sedlis A, Bundy BN, Rotman MZ, Lentz SS, Muderspach LI, Zaino RJ. A randomized trial of pelvic radiation therapy versus no further therapy in selected patients with stage IB carcinoma of the cervix after radical hysterectomy and pelvic lymphadenectomy: A Gynecologic Oncology Group Study. Gynecol Oncol. 1999;73(2):177-83.

38. Monk BJ, Wang J, Im S, Stock RJ, Peters WA 3rd, Liu PY, et al. Rethinking the use of radiation and chemotherapy after radical hysterectomy: a clinical-pathologic analysis of a Gynecologic Oncology Group/Southwest Oncology Group/Radiation Therapy Oncology Group trial. Gynecol Oncol. 2005;96(3):721-8.

39. Guidelines N. NCCN Clinical Practice Guidelines in Oncology - Cervical Cancer. 2013 [cited 2013]; Available from: http://www.nccn.org/ professionals/physician_gls/pdf/cervical.pdf.

40. Leblanc E, Gauthier H, Querleu D, Ferron G, Zerdoud S, Morice P, et al. Accuracy of 18-fluoro-2-deoxy-D-glucose positron emission tomography in the pretherapeutic detection of occult para-aortic node involvement in patients with a locally advanced cervical carcinoma. Ann Surg Oncol. 2011;18(8):2302-9.

41. Gouy S, Morice P, Narducci F, Uzan C, Martinez A, Rey A, et al. Prospective multicenter study evaluating the survival of patients with locally advanced cervical cancer undergoing laparoscopic paraaortic lymphadenectomy before chemoradiotherapy in the era of positron emission tomography imaging. J Clin Oncol. 2013;31(24):3026-33.

42. Potish RA, Downey GO, Adcock LL, Prem KA, Twiggs LB. The role of surgical debulking in cancer of the uterine cervix. Int J Radiat Oncol Biol Phys. 1989;17(5):979-84.

43. Gold MA, Tian C, Whitney CW, Rose PG, Lanciano R. Surgical versus radiographic determination of para-aortic lymph node metastases before chemoradiation for locally advanced cervical carcinoma: a Gynecologic Oncology Group Study. Cancer. 2008;112(9):1954-63.

44. Köhler C, Tozzi R, Klemm P, Schneider A. Laparoscopic paraaortic left-sided transperitoneal infrarenal lymphadenectomy in patients with gynecologic malignancies: technique and results. Gynecol Oncol. 2003;91(1):139-48

45. Surgical Staging in Cervical Cancer Prior to Chemoradiation (uterus11) - NCT01049100 [database on the Internet]. Clinical Trials - U.S. National Institutes of Health. [cited 2011]. Available from: http://clinicaltrials.gov/ct2/show/NCT01049100?term= marnitz\&rank=1

Received: 20/12/2014

Accepted for publication: 18/02/2015

Conflict of interest: none.

Source of funding: none.

Mailing address:

Audrey Tieko Tsunoda

E-mail: atsunoda@hcancerbarretos.com.br / atsunoda@gmail.com 